\title{
Comparison and Contrast of the Elimination Campaigns for Poliomyelitis and Leprosy: Which is More Feasible?
}

\author{
Comparação das Campanhas de Eliminação da Lepra e \\ Poliomielite: Qual é Mais Viável?
}

\author{
Luís MALHEIRO $\rrbracket^{1,2}$, Sofia Correia PINTO ${ }^{3}$, António SARMENTO ${ }^{1,2}$, Lurdes SANTOS ${ }^{1,2}$
}

Acta Med Port 2016 Apr;29(4):279-283 - http://dx.doi.org/10.20344/amp.7364

\section{ABSTRACT}

As we approach the third decade since the WHO started addressing the eradication of poliomyelitis and leprosy, a reflection of the previous campaigns efficacy and an evaluation of further elimination feasibility is important to adapt and intensify the next steps. We performed a critical review of the poliomyelitis and leprosy eradication campaigns to evaluate their technical and operational feasibilities. Vaccination and active case search are highly effective tools against poliomyelitis. If political stability and good vaccination coverage is achieved, poliomyelitis will be an easy target for eradication. Leprosy, on the other hand, faces many barriers towards elimination. The lack of a high efficacy vaccine, the long asymptomatic but infective period, the lack of screening tests and a poorly established elimination target, prevents this disease from being eliminated. In a world where resources and funding are limited, it is apparent that poliomyelitis is a more feasible target for elimination than leprosy.

Keywords: Communicable Disease Control; Disease Eradication; Leprosy; Poliomyelitis; Program Evaluation.

\section{RESUMO}

Com o aproximar da terceira década desde o início das campanhas de erradicação da poliomielite e lepra promovidas pela Organização Mundial de Saúde, uma reflexão sobre a eficácia das campanhas anteriores e o estudo da factibilidade da eliminação futura é importante para adaptar e intensificar os próximos passos. Neste trabalho realizamos uma revisão crítica sobre estas campanhas de forma a avaliar as suas exequibilidades técnicas e operacionais. A vacinação e a procura de casos ativos são ferramentas muito eficazes contra a poliomielite. Mediante a existência de estabilidade politica e uma boa taxa de cobertura vacinal, a poliomielite será um bom alvo à erradicação. A lepra, no entanto, padece de várias barreiras à eliminação como a ausência de uma vacina altamente eficaz, a existência de um período infecioso assintomático prolongado, a falta de métodos de rastreio e um objetivo de eliminação primariamente mal definido. Em conjunto, estes aspetos previnem a doença de ser facilmente eliminada. Num mundo onde os recursos e o financiamento são limitados, a eliminação da poliomielite parece mais exequível comparativamente à lepra.

Palavras-chave: Avaliação de Programas; Controle de Doenças Transmissíveis; Erradicação de Doenças; Lepra; Poliomielite.

\section{INTRODUCTION}

The World Health Organization (WHO) has been defining strategic plans in order to provide nations with interventions for prevention, control, elimination and eradication of neglected tropical diseases since $1978 .^{1}$

Leprosy, a chronic debilitating infectious disease, whose causal agent is Mycobacterium leprae, is associated with deformity and physical disability leading to severe social stigma. The micro-organism is slow-growing and affects the skin and peripheral nerves and, although the disease has been discovered in wild animals, it is believed that humans are the main reservoir. Characterized by a long incubation period of 2-15 years, there is evidence supporting respiratory droplets as the transmission route. Lack of effective screening tests to identify subclinical infections makes case identification difficult and dependable on the clinicians' and patients' suspicion for any skin lesion associated with sensory loss.

Poliomyelitis is a faecal-oral transmitted disease caused by a small RNA poliovirus, characterized by an invasion of the nervous system with consequent acute flaccid paralysis (AFP). Irreversible paralysis in the lower limbs may occur in 1 of every 200 infections. $^{2}$ During the infectious period, the virus is shed in enormous quantities in the throat and intestines of infected individuals. ${ }^{2}$ Two forms of poliomyelitis can be identified, one derived from wild-type poliovirus (WPV-1,2,3), responsible for the disease in endemic areas, and a vaccine-associated poliovirus (VAPV), associated with reactivation of the virus used in the oral vaccine. Case definition for both diseases by the WHO can be found in Table 1.

Being both diseases targets for elimination by the WHO, the aim of this article is to reflect on the elimination programs and compare them in term disease eradicability.

\section{MATERIAL AND METHODS}

A structured search to identify publications on the elimination strategies was performed on PubMed ${ }^{\circledR}$. The keywords used were "leprosy", "poliomyelitis", "elimination", "eradication" and "campaigns". The search identified 198 leprosy-related and 1598 polio-related journal publications. The initial approach was to identify 5 review articles for each disease for an overall understanding followed by a more specific selection to identify potential publications focusing on elimination. Reference lists of important publications

1. Infectious Diseases Department. Centro Hospitalar de São João. Porto. Portugal.

2. Nephrology and Infectious Diseases Research and Development Group, INEB. University of Porto. Porto. Portugal.

3. Unidade de Saúde Familiar de São João. Agrupamentos de Centros de Saúde - Porto Ocidental. Porto. Portugal.

$\triangle$ Autor correspondente: Luís Malheiro. Imalha@gmail.com

Recebido: 04 de janeiro de 2016 - Aceite: 28 de março de 2016 | Copyright @ Ordem dos Médicos 2016 
Table 1 - World Health Organization case definitions for leprosy and poliomyelitis

\begin{tabular}{|c|c|}
\hline Leprosy & Poliomyelitis \\
\hline $\begin{array}{l}\text { Presence of one of the following: } \\
\text { - Loss of sensation in pale or reddish skin lesions } \\
\text { Peripheral nerves with loss of sensation or weakness of the } \\
\text { muscles supplied by that nerve } \\
\text { - Acid fast bacilli in a slit skin smear sample }\end{array}$ & $\begin{array}{l}\text { Child }<15 \text { years of age presenting with acute flaccid paralysis } \\
\text { (AFP) } \\
\text { Or } \\
\text { Any person at any age with paralytic illness if poliomyelitis is } \\
\text { suspected } \\
\frac{\text { Plus }}{\text { Isolation of wild poliovirus in stool specimen of a suspected case }} \\
\text { or contact }\end{array}$ \\
\hline
\end{tabular}

were also scanned. Terms were defined by the WHO criteria: control - reduction of disease incidence to a locally acceptable level, elimination - reduction of the incidence of infection to zero, eradication - permanent worldwide reduction of infection to zero, basic reproductive rate $(\mathrm{R} 0)$ number of secondary infectious cases produced by a single infectious case in a susceptible population. ${ }^{3}$ The criteria used for assessing the feasibility of disease elimination can be found in Table 2. Ethical committee approval was not necessary as no data from patients was collected.

\section{RESULTS}

\section{The way to elimination}

\section{A) Campaigns for Poliomyelitis}

In 1988, a Global Polio Eradication Initiative (GPEI) was created by the WHO to eliminate WPV as it was endemic in 125 countries, with an estimated global prevalence of 10-12 million cases every year. ${ }^{4}$ The strategy aimed at the interruption of endemic transmission of poliovirus having four key points: herd immunization through vaccination, booster immunization, active case finding and surveillance and "mop-up" campaigns in focal high-endemic areas. ${ }^{5}$

A sequence of successes was noticed soon after: eradication of polio in Peru by 1991, the Americas in 1994, the Western Pacific Region in 2000 and Europe in $2002 .^{6-8}$ Poliomyelitis was further eliminated from Niger and Egypt, but by the year 2006 it still remained endemic in four countries: Pakistan, Afghanistan, India and Nigeria, with several outbreaks due to imported cases occurring in previously polio-free countries.
The last country to achieve elimination was India, in 2012, leaving the world with only 3 countries reporting endemic poliomyelitis. The path to elimination requires a timely approach to the needs of a country, as was seen in the successful Indian elimination campaign. Some years after the start of the vaccination program, eradication of the WPV-2 was achieved with the trivalent OPV (tOPV), which had a higher efficacy against this serotype. However, even after a $94 \%$ vaccine coverage was achieved, more than $95 \%$ of the children with active poliomyelitis had in fact received at least 4 tOPV doses earlier on, revealing the extremely poor efficacy of the trivalent vaccine on the other serotypes ${ }^{9}$. The last cases of WPV-3 in 2010 and WPV-1 in 2011 only occurred after the introduction of the higher efficacy monovalent wild-polio virus-1 and 2 (WPV1 and WPV-2) vaccines in 2007, and later on, the bivalent OPV (bOPV). These efforts, however, were only achieved in association with efficient mapping of high-risk blocks in hyperendemic regions, better sanitation and an "active surveillance" program of children under-15 with AFP. ${ }^{10}$ Vaccination regimens and coverage were maintained and India was finally considered free of wild-type poliomyelitis after 2 years of null cases of AFP and negative sewage waters in major Indian cities for WPV. ${ }^{11}$

\section{B) Campaigns for Leprosy}

The elimination of leprosy was defined by the WHO as the reduction of the number of cases to less than 1 case per 10.000 population assuming that it would prevent transmission. The strategy was to establish specific

Table 2 - Criteria for assessing the eradicability of a disease ${ }^{3}$

1) Scientific/Technical feasibility

Epidemiologic susceptibility (e.g., no nonhuman reservoir, ease of spread, naturally induced immunity, ease of diagnosis)

- Effective, practical intervention available (e.g., vaccine, curative treatment)

- Demonstrated feasibility of elimination (e.g., documented elimination from island or other geographic unit)

2) Operational Feasibility

Political will and popular support

Perceived burden of the disease (e.g., extent, deaths, other effects; relevance to rich and poor countries)

- Expected cost of eradication

- Synergy of eradication efforts with other interventions (e.g., potential for added benefits or savings)

Need for eradication rather than control 
programs such as the Leprosy Elimination Campaigns (LEC) which were based in enhanced diagnosis, provision of free multi-drug treatment (MDT) (rifampicin, clofazimine and dapsone), follow-up care, community based counselling and education in order to reduce stigma while increasing self-report. ${ }^{12}$ These sole efforts managed to reduce the disease prevalence to 2.7 million by $1994 .^{13}$

At the beginning of 2013, the WHO reports revealed that the current global prevalence of leprosy stood at 189.018 cases, while the incidence during 2012 was $232.857 .{ }^{14}$ This incidence derives from high-endemic foci like Angola, Brazil and India, with some countries considered to have eliminated leprosy such as the Democratic Republic of Congo (DRC) and Mozambique also exhibiting some high endemicity foci.

\section{DISCUSSION}

When comparing leprosy and poliomyelitis elimination campaigns, both technical and operational feasibility should be assessed. Technical feasibility depends on the disease biology and interventions efficacy to interrupt disease transmission; operational feasibility depends on human capital, infrastructures, and political commitment in order to reach the elimination goals. Table 3 resumes the biological characteristics of both diseases on which technical feasibility depends.

\section{Technical Feasibility}

Epidemiological susceptibility - While both diseases have good diagnostic criteria for active disease and no relevant non-human reservoir, they differ in infectivity. Poliomyelitis is a self-limited disease, and viral shedding has a limited duration, while leprosy is a chronic disease, and probably infective throughout the whole disease process. Leprosy also lacks reliable laboratory tests to detect subclinical infection, which renders it harder to diagnose when asymptomatic, but still infective. The incubation period may be as long as 2-15 years and new patients may continue to present after successful control campaigns have ended.

However, while poliomyelitis is highly infective, with an estimated $\mathrm{RO}$ as high as $10-15$, in a non-vaccinated population with circulating WPV, the basic reproductive rate for leprosy has not been previously estimated since there is no universally accepted test for subclinical infection. However it is estimated to be $1.5-4$, depending on the setting. ${ }^{15}$

Practical interventions' availability - While a curative approach does not exist for poliomyelitis, being the treatment supportive, several vaccines with different efficacies addressing the three serotypes exist and are available. On the other hand, leprosy has no vaccination available, but it has an available treatment with $98 \%$ efficacy. ${ }^{17}$

Treatment for leprosy with MDT not only has a high efficacy, but also shortens the duration of infectivity and therefore reduces the risk of further transmission to healthy individuals in the community. ${ }^{21}$

An aspect to remember is that, to achieve true polio eradication, transmission should be zero not only for WPVs but also VAPV. Even though rarely (one case per 750000 doses), tOPV is associated with vaccine-induced paralysis as the attenuated virus may mutate and regain neurovirulence and transmissibility. ${ }^{18-20}$ After WPV elimination, it is no longer correct to continue immunization with OPV and therefore it should be substituted with the inactivated poliovirus vaccine (IPV), especially in countries using bOPV, which does not confer immunity against a re-emergence of WPV-2. Even though IPV is more expensive and does not confer strong herd immunity, it is efficient against all types of WPV. ${ }^{15}$ Nevertheless, eradication will only be achievable if after elimination, vaccination programs are maintained to keep herd immunity against imported cases.

It has been suggested that Bacillus Calmette-Guérin vaccine could help the leprosy campaigns, but as it is

Table 3 - Biological characteristics of leprosy and poliomyelitis ${ }^{15,16}$

\begin{tabular}{|c|c|c|}
\hline & Leprosy & Poliomyelitis \\
\hline Vaccine & None available & OPV or IPV \\
\hline Infection transmission & $\begin{array}{l}\text { Infective throughout all the incubation period } \\
\text { and active disease without treatment }\end{array}$ & $\begin{array}{l}\text { Sheds virus in faeces for at least } 3 \text { weeks (may last } \\
\text { to } 4 \text { months) } \\
\text { No long term carrier }\end{array}$ \\
\hline Subclinical infection & Incubation period of $2-15$ years & $95 \%$ of the cases are asymptomatic. \\
\hline Natural induced immunity & None & $\begin{array}{l}\text { Some homotypic immunity, but not complete. No } \\
\text { heterotypic immunity }\end{array}$ \\
\hline Non-human reservoir & Possible reservoir in animals & None \\
\hline Diagnosis & Criteria available & $\begin{array}{l}\text { Criteria available } \\
95 \% \text { asymptomatic }\end{array}$ \\
\hline Reproductive Rate & $\begin{array}{l}\mathrm{R} 0 \text { is unquantified but is theoretically estimated } \\
\text { to be between } 1.5-4 \text { depending on the setting }\end{array}$ & R0: $10-15$ \\
\hline Treatment & High efficacy multi-drug therapy & Symptomatic only \\
\hline
\end{tabular}

OPV: oral poliomyelitis vaccine; IPV: inactivated poliomyelitis vaccine; R0: reproductive rate. 
already widespread in endemic countries, may not be as useful as expected. ${ }^{21}$

\section{Operational feasibility}

While both diseases had a high prevalence and high morbidity rates associated, which targeted them for elimination by the WHO, previous elimination campaigns have shown that they greatly depend on the setting and political and social support.

In 2012, three countries were still considered to be polioendemic: Nigeria and Pakistan with WPV types 1 and 3 and Afghanistan with WPV type 1. General operational reasons identified during the last 20 years that prevent eradication can be found in Table 4, as well as some solutions..$^{20}$ It seems that the most important factor for delaying eradication is poor vaccination coverage of the paediatric population. Reasons are migration, isolated populations and regions where conflict is apparent such as Pakistan and Southern Afghanistan, where vaccination campaigns are often cancelled or not planned due to safety reasons.

During the past decade, 40 countries developed outbreaks of poliomyelitis due to imported WPVs. As long as WPVs circulate anywhere, these may re-infect polio-free countries. These aspects reveal that operational feasibility is highly dependent on political stability and support to block importation of new cases post-elimination.
Leprosy campaigns committed governments, donors, and health workers to focus on leprosy and facilitated free drug treatment. ${ }^{22}$ However, the last WHO report on the Global Leprosy situation showed that, not only incidence has not significantly dropped since 2005 but also that the proportion of patients presenting with advanced disability is still high. ${ }^{14}$ As elimination was not defined to be zero cases, many countries where elimination was achieved still report new cases every year, as transmission is not truly interrupted despite the public perception of elimination. In Peru, for instance, the loss of active-case search and contact screening, lead to occult leprosy prevalence and patients presenting late in their disease. Lockwood et al, recently addressed the Brazilian omission of active cases in order to fulfil the WHO objectives of elimination. Her reflections suggested that objectives must be transparent as workers aim to reach targets in the most unexpected ways, with the penalty of compromising the campaigns efforts. ${ }^{23}$

Given this, one of the key objectives of the current leprosy plan is to keep treating all people who have this disease, and that, even though a country may achieve elimination as defined by the WHO, further campaigns are still needed and should not be forgotten by the authorities and donors after elimination.

\section{CONCLUSIONS}

(NC, 2003)

\begin{tabular}{ll}
\hline Challenge & Response \\
\hline Poor tOPV immuno-genicity & Introduction of mOPV and bOPV
\end{tabular}

High vaccine coverage

\author{
Surveillance sensitivity and \\ timeliness
}

\section{Emerging immunity gaps and polio outbreaks}

Waning intestinal immunity

Vaccine-associated poliovirus (VAPV) outbreaks

\author{
Re-emergence of poliovirus \\ post-eradication
}

Improved post-campaign monitoring

New management practices

Community engagement

Increased technical assistance

Strengthened routine immunization

Innovations in vaccine delivery (e.g. short-interval campaigns, fixed vaccination posts, etc.)

Faster laboratory protocols

Expanded environmental surveillance

Improved sensitivity to detect vaccine-derived polioviruses

Risk assessment and prioritization of vaccination campaigns

Faster response to outbreaks

Strengthened routine immunization

Studies to assess the importance of waning intestinal immunity for poliovirus persistence and potential strategies to boost mucosal immunity

Coordinated OPV cessation

Accelerated endgame strategy to sequentially remove spread poliovirus serotypes from OPV, starting with serotype 2

Rapid response to VAPV outbreaks, equivalent to response to wild-type poliovirus

Global action plan on poliovirus containment

Screening of individuals with primary immunodeficiency for VAPV shedding

Recommended universal introduction of routine immunization with at least one dose of IPV

tOPV: trivalent oral poliomyelitis vaccine; bOPV: bivalent oral poliomyelitis vaccine; VAPV: vaccine-associated polioVirus; IPV: inactivated poliomyelitis vaccine. 
As we are approaching the third decade since the WHO began addressing these problems, a reflection on the previous campaigns efficacy and an evaluation of further elimination feasibility is important to adapt and intensify the following steps. The world has great tools against poliomyelitis as vaccination and active-case search are highly effective. If political stability and good vaccination coverage is achieved, in the next years, poliomyelitis will be a great candidate for eradication. Leprosy, on the other hand, faces many barriers towards elimination. The lack of a high efficacy vaccine, the long asymptomatic but infective period, the lack of screening tests and a poorly established elimination target, delays the elimination of this disease. In a world where resources and funding are limited, it is apparent that poliomyelitis is a more feasible target for elimination than leprosy. As for the latter, in order to achieve elimination, campaign remodelling and intensification, with long lasting screening, active case search, and reasonable targets, adapted to a disease with a long incubation period, should be defined. However, it seems that it will take long until we reach true elimination.

\section{Contributors and Authorship}

Luís Malheiro was responsible for the conception and design of the study, acquisition of data, analysis and interpretation of data and drafting of the article. Sofia Correia Pinto and Lurdes Santos were responsible for analysis and interpretation of data, and critical revision for important intellectual content.

All authors have approved the final article.

\section{PROTECTION OF HUMANS AND ANIMALS}

The authors declare that the procedures were followed according to the regulations established by the Clinical Research and Ethics Committee and to the Helsinki Declaration of the World Medical Association.

\section{DATA CONFIDENTIALITY:}

The authors declare having followed the protocols in use at their working center regarding patient's data publication.

\section{CONFLICTS OF INTEREST}

The authors declare that there are no conflicts of interest.

\section{FUNDING SOURCES}

This research received no specific grant from any funding agency in the public, commercial, or not-for-profit sectors.

Morb Mortal Wkly Rep. 2011;60:1482-6.

12. World Health Organization. Global strategy for further reducing the leprosy burden and sustaining leprosy control activities (plan period: 2006-2010). Geneva: WHO; 2005

13. World Health Organization. Chemotherapy of leprosy: report of a WHO study group. WHO technical report series, 847. Geneva: WHO; 1994.

14. World Health Organization. Wkly Epidemiol Rec. 2013;88:365-80.

15. Fine PEM, Carneiro IAM. Transmissibility and persistence of oral polio vaccine viruses: implications for the global poliomyelitis eradication initiative. Am J Epidemiol. 1999;150:1001-21.

16. Fine PEM. Leprosy: the epidemiology of a slow bacterium. Epidemiol Rev. 1982; 4:161-88

17. Scollard DM, Adams LB, Gillis TP, Krahenbuhl JL, Truman RW, Williams DL. The continuing challenges of leprosy. Clin Microbiol Rev. 2006;19:338-81.

18. Kohler KA, Banerjee K, Hlady WG, Andrus JK, Sutter RW. Vaccineassociated paralytic poliomyelitis in India during 1999: decreased risk despite massive use of oral polio vaccine. Bull World Health Organ. 2002;80:210-6.

19. John TJ. Vaccine-associated paralytic poliomyelitis in India. Bull World Health Organ. 2002;80:917.

20. Grassly NC. The final stages of the global eradication of poliomyelitis 2013. Phil Trans R Soc B. 2013;368:20120140.

21. Lockwood DNJ, Suneetha S. Leprosy: Too complex a disease for a simple elimination paradigm. Bull World Health Organ. 2005;83:230-5.

22. World Health Organization. Who donated MDT. [consulted 2015 December 1] Available from: http://www.who.int/lep/mdt/donation/en/ index.html.

23. Lockwood DNJ, Shetty V, Penna GO. Hazards of setting targets to eliminate disease: lessons from the leprosy elimination campaign. BMJ. 2014;348:g1136. 